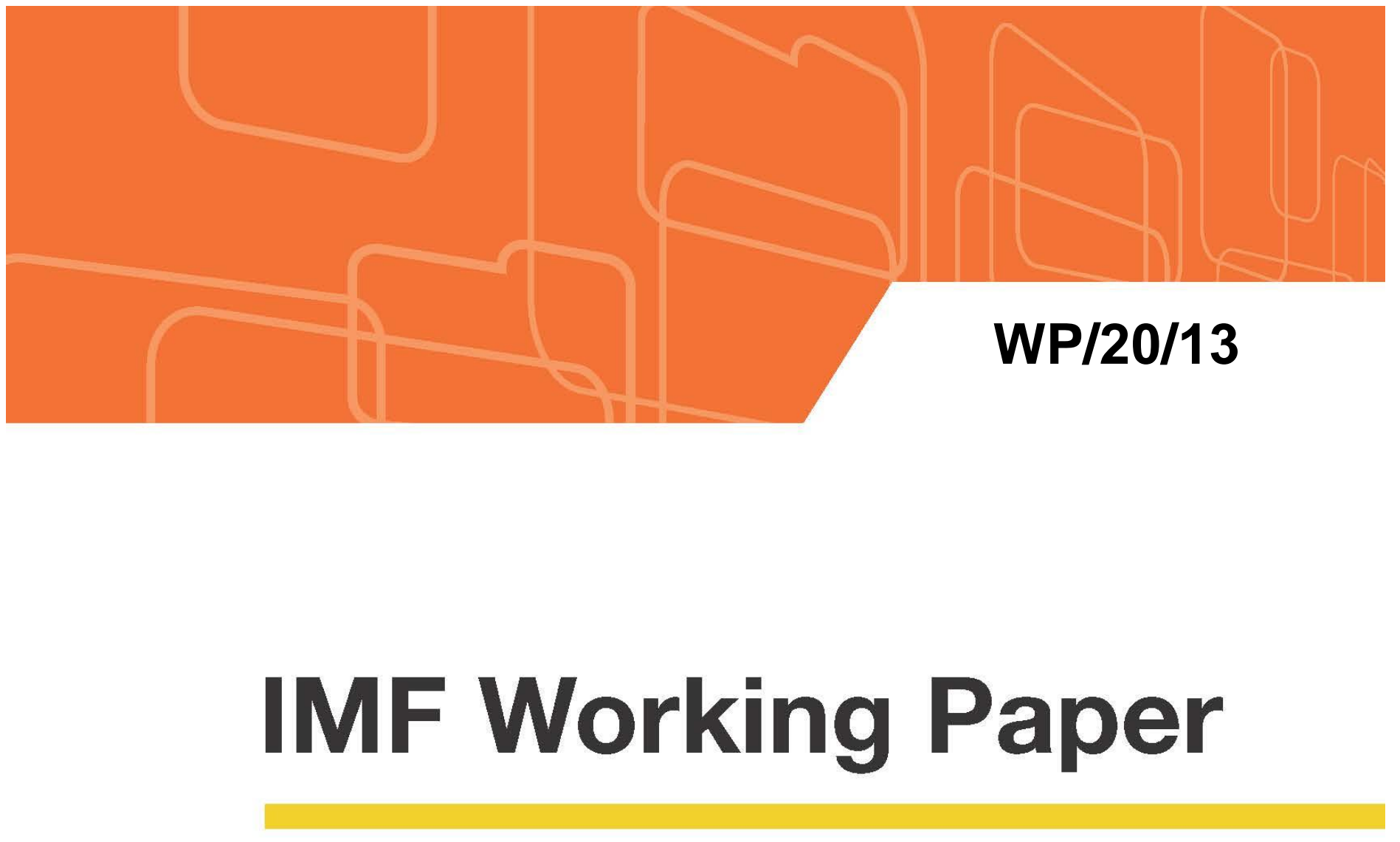

\title{
A Monthly Indicator of Economic Growth for Low Income Countries
}

by Michael Stanger

IMF Working Papers describe research in progress by the author(s) and are published to elicit comments and to encourage debate. The views expressed in IMF Working Papers are those of the author(s) and do not necessarily represent the views of the IMF, its Executive Board, or IMF management. 


\title{
IMF Working Paper
}

Statistics Department

\section{A Monthly Indicator of Economic Growth for Low Income Countries Prepared by Michael Stanger}

\author{
Authorized for distribution by James Tebrake
}

January 2020

IMF Working Papers describe research in progress by the author(s) and are published to elicit comments and to encourage debate. The views expressed in IMF Working Papers are those of the author(s) and do not necessarily represent the views of the IMF, its Executive Board, or IMF management.

\footnotetext{
Abstract

Monthly economic indicators support policy analysis of current economic developments and forecasting. This paper presents an overview of the data and statistical requirements to develop those indicators taking into account resource constraints that LIC typically face. We review statistical procedures for developing these indicators under the System of National Accounts and propose a general procedure to derive a monthly composite indicator of economic growth in low income economies.

JEL Classification Numbers: E01, E23

Keywords: Economic activity, System of National Accounts, GDP

Author's E-Mail Address: MStanger@imf.org
} 


\section{Contents}

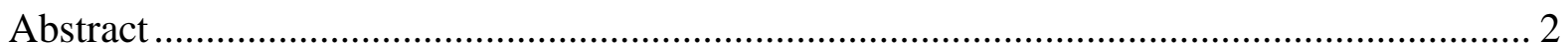

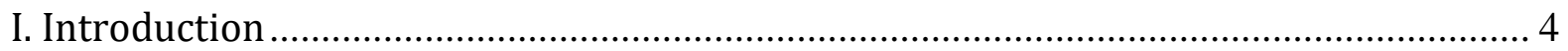

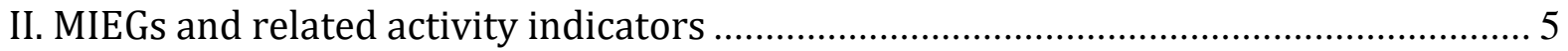

III. Measuring economic activity under the SNA framework ............................................. 7

IV. IMF's MIEG capacity development ........................................................................... 9

V. Developing a Monthly Indicator of Economic Growth .................................................. 12

A. Stock take of source data ............................................................................................... 13

B. Assessment and selection of indicators....................................................................... 14

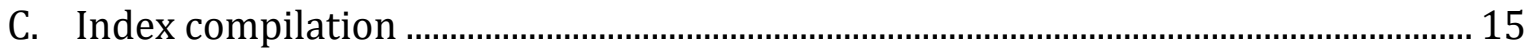

D. Index dissemination ....................................................................................................... 17

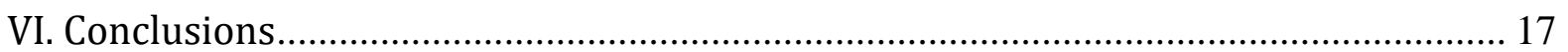

Appendix 1: Available indicators by country (to be completed) .......................................... 19

Appendix 2: Detailed data sources and indicators by type of industry.................................. 20

Appendix 3: Availability of statistics by geographical area ................................................ 22

Appendix 4: Other High Frequency Indicators of Activity ............................................... 23

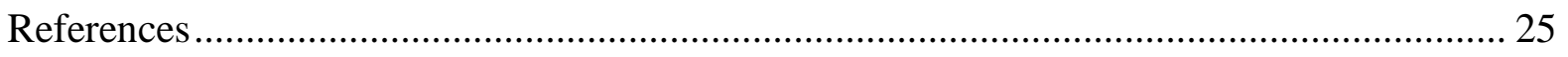




\section{Introduction}

Monitoring economic activity is a key policy task. The state at which an economy is producing and using its resources is fundamental to determine its health. Measuring economic activity is thus essential to support policy decision making, and timely policies or corrective measures require timely measures. Given the deep economic transformations of many economies in the world in the last decades, traditional partial indicators seem to no longer work as good proxies for economic activity.

The International Monetary Fund (IMF) in its supervisory role has introduced the Data Standards Initiatives (DSI) to promote transparency of economic and financial statistics and to facilitate surveillance. The Special Data Dissemination Standard (SDDS, and SDDS Plus) prescribes a set of statistics that are required for surveillance, including GDP and prices. It also prescribes monthly production indexes intended for short term analysis and as an early estimate of the target variable Quarterly GDP. Although not prescriptive, the Enhanced General Data Dissemination System e-GDDS also recommends this monthly index.

International standards provide very comprehensive and standardized set or recommendations for measuring economic activity as the action of production in which inputs are used to produce output. However, depending on data availability and resources, countries may only compile and thus relay on annual or quarterly estimates of economic activity to conduct policies.

This paper focuses on the data and statistical requisites of indicators aimed at producing timely comprehensive measures of economic growth, these are referred to as monthly indicators of economic growth (MIEG). Although not called monthly GDP, several countries produce and disseminate comprehensive measures of economic activity. These indicators are largely based on quantitative source data, including related high frequency indicators, and based on the statistical framework of the national accounts.

MIEGs are a very specific type of high frequency indicator that aims at providing a timely signal of economic growth on a monthly basis. They differ from business conditions or consumer confidence indexes, or from business-cycle indicators such as those published by the Conference Board ${ }^{1}$ and the composite indicators by

\footnotetext{
${ }^{1}$ https://www.conference-board.org/about/index.cfm?id=1980
} 
published by the $\mathrm{OECD}^{2}$ in that they are almost exclusively derived from quantitative source data, largely comply with international methodological standards, and are targeted to concurrent measures of activity -as opposed to anticipating changes in the business cycle exclusively. Moreover, MIEGs are broader in coverage, facilitate comparability among countries, and enable contribution analyses.

Countries where these indicators are available show that these timely comprehensive measures of economic growth serve various purposes. First and foremost, they provide a very up to date signal of the economy from which policy and business cycle analysis can be drown. They also support forecast of activity since they are disseminated ahead of more structural measures of activity. Given their contemporaneousness, they are also used to assess the effect of previous policy measures and to analyze public budgetary programs that are based on assumptions about economic growth (or forecasts). Finally, depending on the detail at which these indicators are disseminated, they can provide more granular information about the drivers of the changes in growth.

Following this introduction, the paper will briefly describe MIEGs and other known activity indicators, and further describe economic activity measurements under the SNA framework. Next, it will note some of the IMF's capacity development involvement on MIEGs. To finalize, a short section on how to develop a MIEG precedes the final conclusions.

\section{MIEGs and related activity indicators}

Some economic indicators have historically been broadly used to track the current status of the economy or to grasp signals about the business cycle. For instance, most countries compile monthly CPIs and use it extensively for assessing inflation, monetary policy, and as GDP deflator. This indicator is reported by about 95 percent of the IMF member countries. However, for economic activity, most countries rely on quarterly or annual estimates of "real"3 GDP, or on partial related indicators.

Traditionally, the industrial production index (IPI) has been used as a proxy of economic activity, however has progressively lost its capacity to represent the economy as a whole in most industrialized countries. The rise of service activities and

\footnotetext{
${ }^{2}$ Prominent examples of composite indicators that are based on both quantitative and qualitative data are those compiled by the US Conference Broad and the Organisation for Economic Cooperation and Development (OECD) (Appendix 1).

${ }^{3}$ The term real is used as a substitute of constant prices or chained volume.
} 
the increased volatility of commodity prices have led to more frequent shifts in the economic structure of economies and this has limited the usefulness of this indicators since the reflect a smaller and smaller portion of overall economic activity. Only about 60 percent of the IMF member countries report such an index. Other activity-specific indicators serving as proxies include subsets of the IPI (e.g. electricity production), agricultural products production, or retail sales.

Countries with more sophisticated statistical systems have overcome this gap by developing business cycle indicators as a way of having a more complete view of the economy as a whole (more detail in Appendix 4). The objective of these indicators is to represent one of the components of the economic activity, the cycle ${ }^{4}$, or the changes thereof. Some of these cycle-tracking indicators aim at anticipating the changes in the cycle (leading5) while other aim at a concurrent detection of changes. There are also, indicators intended to confirm cycle changes (lagging).

As complementary data to anticipate changes in the cycle, counties started developing expectations and sentiments indicators. These are designed to represent the average "feeling" about the near future, which in turn are expected to trigger behavioral relationships that will affect economic activity. These data, along with other related quantitative indicators such as interest rates, stock prices, money supply, production orders (to mention some) are also used as input data in some of the cyclical indicators.

MIEG is intended to measure economic activity and thus relies more heavily on records of transactions that are directly related to the activity under question and are generally aggregated using well established statistical frameworks. ${ }^{6}$ For instance, actual sales (record) are more directly related to activity than pervious expected consumption (behavioral expectation). Quantitative measures of activity, like production, sales, exports, or employment are key inputs into the development of MIEGs. These source data are generally obtained from surveys or administrative records.

\footnotetext{
${ }^{4}$ The cycle is one of the components of a time series. It is broadly agreed that time series are composed of a trend, a cycle, a seasonal (including calendar) and an irregular component.

${ }^{5}$ Leading indicators are increasingly popular as complements to econometric models which generally fail to detect turning points.

${ }^{6}$ A prominent example of a composite measure of economic activity based on quantitative data is the quarterly GDP.
} 
Table 1: Examples of Activity indicators according to source data and aggregation methods

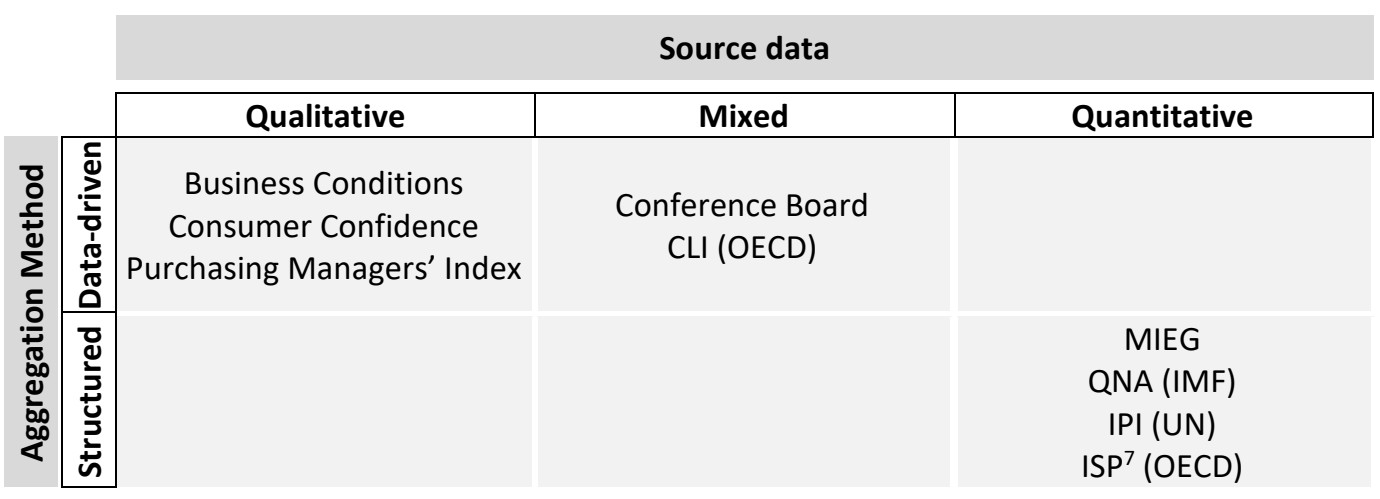

Business cycle indicators start playing a relevant complementary role in countries with well-established statistical systems. These indicators generally require the management of administrative records, more sophisticated modeling procedures, and a higher level of statistical infrastructure. Countries with this capacity will generally have good systems to track the economic activity, either by means of a set of several indicators related to activity or by some few robust macro indicators. However, for countries with less developed systems of data management, the initial step should be developing monthly or quarterly economic activity indicators that reflect as close as possible actual developments.

For some LIC improving the capacity to track the latest activity developments will imply developing monthly or quarterly activity indicators that represent the most significant parts of the economy -as an intermediate step prior developing more comprehensive QNA-, improving the quality of already existing indicators, and expanding the coverage of the indicators (go beyond the IPI) up to implementing a MIEG. Only then the predictive power of forward looking indicators can be assessed.

\section{Measuring economic activity under the SNA framework}

MIEGs are based on the SNA methodology and such are as consistent as possible with other macroeconomic statistics such as the quarterly and annual national accounts aggregates. This methodology follows a bottom-up approach and promotes the use of well-established classification systems under which all the components of an aggregate are compiled and are based on consistent available data sources. For instance, GDP requires the estimation of each of its component (industries

${ }^{7}$ The Index of Services Production measures short-term production activities of the services industry. 
or expenditure components). ${ }^{8}$ The level of detail at which components are estimated depends on input and structural data availability. For instance, it is expected that quarterly GDP is less detailed than annual GDP. Also, as the focus is the economic activity real growth, data in nominal value terms need to be deflated (prices effects removed) so that the estimated components are in volume terms.

The compilation of these aggregate indicators starts with the collection or development of detailed quantitative source data that are directly related to the intended variables. Granular source data is then processed and aggregated to develop elementary indicators. These elementary components are then combined using some index-type formulation to derive the aggregates. Input data is obtained either directly from surveys or as by-product of administrative records. It can be collected directly in volume terms or as values. Data in values have to be deflated with appropriate prices and methods before any further aggregation. The aggregation is carried out using weights that are derived from consistent structural figures such as the national accounts, annual economic surveys, or economic censuses. Additional sophistication can be incorporated to the compilation to improve the statistical quality of the estimates by applying enhancements similar to those used in QNA estimation. ${ }^{9}$

The bottom-up approach requires estimated measures of all components of the aggregates. Most countries have high-frequency direct information available for some components of the economy (such as the IPI). Other components need to be built from available sources notwithstanding the need to deviate from the intended concept to measured. For instance, for activities strongly engaged in exports, the related information to measure production could be the exports from customs records as opposed as the output measure. However, inventories can have a significant role in explaining divergences between production and exports in these activities. Whether related indicators are directly available or need to be compiled, their quality must be tested against the target variable.

\section{Statistical procedures, informed assumptions, and modeling are largely} required to overcome potential weakness of source data. High frequency data for certain components can either be unavailable or be of poor quality. It can also be the case that multiple sources with various quality degrees are available for the same component. Data gaps can be filled by estimates based on related information and using diverse methods and statistical procedures such as econometric modeling (time series

\footnotetext{
${ }^{8}$ For the production approach, indicators should represent each economic activity. For instance, to measure retail sales margins in volume terms, it would be necessary to have total retail sales and their related deflators. For the expenditure approach, indicators should cover the expenditure components, such as exports and imports and as their respective prices. The income approach to measuring GDP has been omitted since it is not intended for volume estimates.

${ }^{9}$ Benchmarking technics to reconcile high frequency information with the lower frequency counterparts is one example. In addition, Benchmarking allows an update weights over time.
} 
regressions). Multiple sources could be combined using statistical procedures (e.g. principal components). Even when actual transaction records may be available (including survey data), deriving elementary indicators could require outlier detection and validation procedures. The timeliness of source data is a key decision factor regarding the usage of alternative elementary components and methods.

MIEGs provide the grounds for timely monthly business cycle analysis. Observed quantitative data assembled using international statistical standards will broadly generate a consistent indicator that mirrors actual economic developments on a monthly basis. With some additional processing, users will be enabled to derive trendcycle estimates or to apply usual filters to smooth-out desired signals. Moreover, trendcycle estimates derived from MIEGs can serve as benchmark for (leading) businesscycle estimates.

\section{IMF's MIEG capacity development}

Most of the countries that report production indexes to the IMF (about 125) do it on a monthly basis. However, only a small set of these compile and disseminate a comprehensive MIEG (see Appendix 1 to see a non-exhaustive list of countries currently disseminating a MIEG). ${ }^{10}$ The large majority of reporting countries compile an IPI, a reduced version of it, or another activity-specific indicator. By definition, the IPI covers manufacturing, mining, and electricity, gas, water and waste management as shown in Table 2. Other activity-specific indicators include construction, retail sales, tourism, and agriculture products. These partial indicators represent a good starting point to enhance the coverage and quality of monthly activity indicators.

Even though the number of countries compiling high-frequency production indices may seem relatively high, quality issues and low significance in the current economic stance may be affecting their relevance and usefulness. About 35 percent of the IMF member countries do not have a high-frequency indicator of activity. And from the 65 percent of countries that do produce at least one, most are only partial, are often outdated, lack timelines, or do not necessarily track economic activity as reflected in GDP. To enhance good and timely policy development in LIC as well as own countries capacity to assess the economy and inform policy, the IMF started

\footnotetext{
${ }^{10}$ A significant number of countries produce some type of economic growth indicator but are not publicly disseminated.
} 
supporting countries to improve, update, and develop high-frequency indicators of economic activity.

\section{Capacity development (CD) in the form of technical assistance (TA) missions and training courses ${ }^{11}$ on MIEG are part of the IMF Statistics Department (STA)} program since 2013. TA has focused on supporting countries improve indicators that are already available, develop experimental additional indicators with available source data, and in compiling a comprehensive MIEG whose coverage includes broad activity components as shown in Table 2 (12 activities). ${ }^{12} \mathrm{~A}$ number of countries have made progress in developing MIEG. For example, Colombia released a comprehensive monthly indicator of the economic activity, the Economic Tracking Index for the first time, in 2014.

Table 2: Inputs to a Monthly Indicator of Economic Activity

Activity $^{\mathrm{a}}$

\begin{tabular}{|l|l|}
\hline Agriculture, forestry and fishing & Commodity production - Exports \\
\hline Manufacturing and Mining & Index of industrial production \\
\hline $\begin{array}{l}\text { Electricity, gas, water and waste management. } \\
\text { Construction }\end{array}$ & Index of industrial production \\
\hline $\begin{array}{l}\text { Trade, Transportation and Accommodation and } \\
\text { food. }\end{array}$ & $\begin{array}{l}\text { Construction index - Imports } \\
\text { Informail and Wholesale index - Tourism index } \\
\text { Inports }\end{array}$ \\
\hline $\begin{array}{l}\text { Financial and insurance activities } \\
\text { Real estate, Professional and Supporting services. }\end{array}$ & Index of services production \\
\hline $\begin{array}{l}\text { Public administration and defense; compulsory } \\
\text { social security }\end{array}$ & Index of services production \\
\hline Education & Government statistics \\
\hline Human health and social work activities & Government statistics \\
\hline Other service activities & Government statistics \\
\hline
\end{tabular}

a: Reduced form of economic activities by sections according to the $I S I C$ rev. 4

b: Examples of already existing HFI for specific activities

\section{A notable example of improvement in the compilation and use of MIEG is}

Guatemala. Although the country had historically relied on a composite index of economic activity for short-term analyses, especially when quarterly GDP was not

\footnotetext{
${ }^{11}$ With the support of the Regional Technical Assistance Centers, the Statistics Department (STA) has provided training to more than 75 countries between 2014 and 2019. Training activities have covered most regions in the world yet focusing on less developed countries where these indicators are absent or are of lower quality so that the impact and contribution are more significant. In 2018, STA started implementing the multi-annual STA Data for Decisions (D4D) trust fund project which includes an HFI workstream. This workstream is aligned with the objectives set for the MIEG.

${ }^{12}$ A more detailed list of sources and indicators by economic activity is available in the Appendix 3.
} 
available, it presented some deterioration as the economic structure of the economy changed more dynamically. By mid-2013, the Guatemalan Central Bank re launched the new MIEG which was compliant with the SNA framework. The index is now presented to the board of the Bank and disseminated publicly with a lag of about 30 days from the reference month.

Guatemala-Update to the MIEG

As shown in Chart 4, Guatemala's new Monthly Indicator of Economic Activity (MIEG) is more in line with the economic activity as reflected in the quarterly GDP.

Chart 4. Guatemala: Comparing old and new MIEG with the QNA.

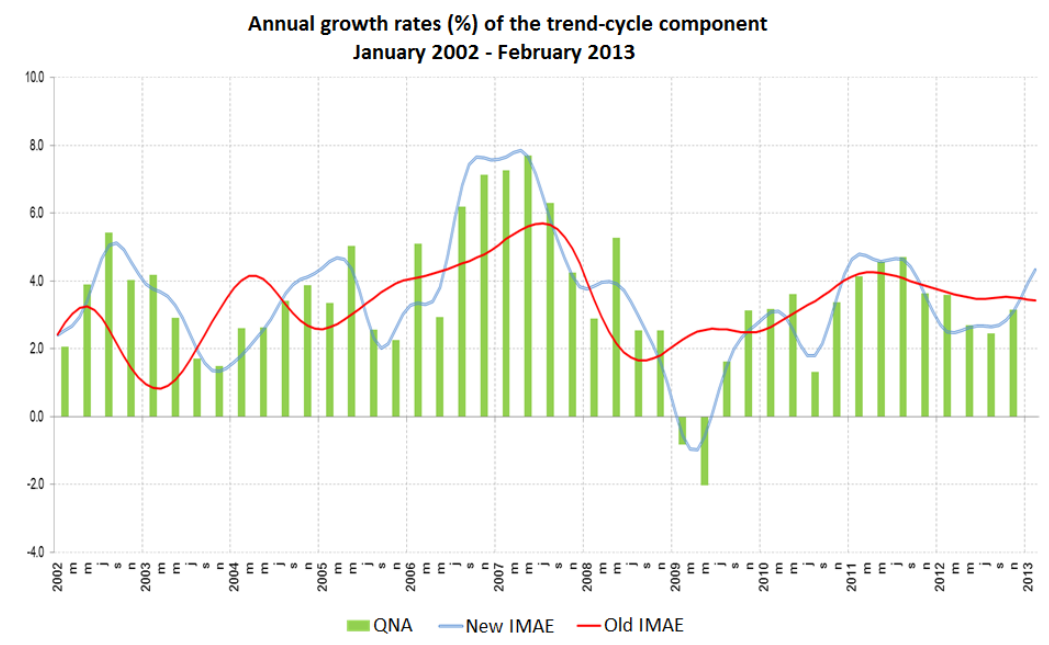

Most countries strive to follow international standards when compiling activity indexes. However, the coverage of such indicators may be restricted to activities that do not represent significant parts of the whole economy and, on the other hand, they are often built independently from the main macroeconomic frameworks sometimes resulting in contradicting signals when compared to more structural measures of the same variable. In addition, metadata for some indices sometimes highlight important deviations from international standards.

The progressive loss of relevance of the industrial activity in many economies combined with the increased amount of available timely and detailed available high frequency source data, have encouraged statistical users and policy makers to demand for additional, better, and timelier indicators. Enabling stakeholders' analyses, supporting informed policy making and prompt policy assessments without neglecting 
international comparability requires methodological standards and classifications. The flexibility of SNA adapts to any country's reality and to any data frequency thus a MIEG is intended to be conceptually comparable among countries regardless their economic development and structure.

\section{Developing a Monthly Indicator of Economic Growth}

The level of detail at which the elementary and activity aggregates are compiled, are bounded by the detail of annual benchmarks available (from which the weighting structure is derived), and by the availability of related high frequency data sources to assemble them. Ideally, the same level of detail is available for both datasets, that is there are as many indicators available as the detail breakdown of the economy, however, in most cases some compromises are required and then some components have to be derived indirectly from related information, have to be estimated using some statistical methods to fill data gaps, or the breakdown be reduced to match the available indicators. Even for cases where components are readily available, they can suffer from various shortcomings. Quality assurance and data gap infilling requires a variety and flexible set of statistical procedures (including time series techniques).

An essential step towards the development of any activity measure is an exhaustive search of available sources and close collaboration with other data producing agencies. Furthermore, continuous efforts to finding new or improve sources will guarantee the quality sustainability of and further enhancements to the indicators and its components. Exploiting source data to maximize the use of available information will also require the use of statistical procedures (validation, depuration, imputation, etc.).

Elementary indicators are directly related to source data and are aimed to represent specific components of the activity and are built from a variety of sources such as survey-based indexes, administrative data, corporation's reports, price indices, labor statistics, government data, international trade statistical, and even big data. These elementary indicators are expected to track the evolution of and be more frequent and timelier than the target variables.

The SNA approach for compiling a MIEG can be seen as an extension of the quarterly GDP compilation on a monthly basis using the Quarterly National Accounts methodology. The index embodies both the short-term evolution of available high frequency industry related indicators and the structural framework of reliable low frequency statistics. Even when economic activity can be measured by both production 
and expenditure, this paper focuses on the production approach as it is more frequently available. A notable example of this practice is the Canadian monthly GDP program (1971), whose monthly GDP series are available from the mid 90's.

Four main steps must be undertaken when developing or updating a MIEG: i) a comprehensive stocktaking of available source data and its timeliness; ii) assessment and selection of indicators; iii) compilation, and; iv) dissemination.

\section{A. Stock take of source data}

The SNA approach requires information for each of the component series (e.g. industries in Table 2). Source data must be available on a monthly basis, with sufficient timeliness, and be as close as possible to the target component in terms of definition and coverage. To support harmonization and international comparison, classifications among all statistical products within the same framework need to be aligned, ideally using the Central Product Classification (CPC) Ver.2.1 and the International Standard Industrial Classification of all Economic Activities (ISIC) Rev.4 for products and activities respectively.

Source data can be grouped into: direct and related data. Direct data are those series that are broadly consistent to the definition of the target component, value added (either output or sales by activity). Related data represent variables that conceptually do not match the target component but are closely related (employment indicators as opposed to output).

Source data series can be available either in quantities or in values. Quantity data contain information on the number of products produced/sold by certain establishment, enterprise or economic activity (e.g. tons of sugar). Value data in turn show the monetary value of the quantities produced/sold, and i.e. include the price dimension (e.g. sales of sugar).

Most common related data are those representing either production inputs or to the destination of output. Among the most common production inputs there are employment indicators or intermediate raw material inputs from other industries or from imports (e.g. imports of wheat for the flour production). Regarding the destination of output, intermediate inputs used by another industry or exports (e.g. exports of fish).

Possible data sources include monthly trade statistics, monthly survey data, administrative records, tax records, monthly labor statistics, big data, and other economic indicators such as the industrial production index, retail trade statistics, and agricultural production. Moreover, when quarterly or annual targets are derived using models or certain assumptions, it may be necessary to apply such procedures on a monthly basis to derive related indicators. 
Given the multiple interrelations within an economy, the different quality properties of the data, and the timeliness requirements of the various possible sources it becomes essential to consider all possible sources of information even when there appear to be no direct connection with the measurements. Related information and indirect relationships may result useful when the need for filling in data gaps.

Data collected during the $\mathrm{CD}$ activities to low and lower-middle income countries show that most countries compile and disseminate industrial production indices and prices statistics. About $3 / 4$ have access to monthly international trade statistics, and about $1 / 2$ have access to VAT data. On average, $1 / 4$ compile and disseminate other activity indicators, however, the dispersion is large. It has also been stated that most countries have unused data available.

\section{B. Assessment and selection of indicators}

As a first quality assurance measure, the concepts and definitions of both the input data and the target variable must coincide, that is, input data must be conceptually related to the intended variable. Spurious relationships have to be avoided. Given that the MIEG is intended as a volume indicator, all elementary and component series have to be derived excluding price effects. Quality changes must be accounted for as volume effects.

For certain products or activities, quantity or volume series can be readily observed. For others however, only current values may be available. Value series must be deflated with an appropriate price index to obtain volume series. Deflation should be carried out at the most detailed level feasible (micro-deflation) so as to derive individual elementary volume measures prior deriving aggregates. This way, quality mixes are more likely accounted for as volume effects. As a general rule, the higher the detail in the level of compilation the more accurate the volume estimate.

Therefore, price statistics would be needed under the same requirements as the activity data. When dealing with rather aggregate series or heterogeneous groups of products, deflated values with plausible prices indexes are preferred to direct volume data. Nevertheless, in the absence of adequate price statistics direct quantity variables are to be preferred.

Volume elementary indicators, either directly collected or derived from deflating values, will be used as inputs to derive the components of the MIEG. These elementary indicators can be subject to additional processing, directly aggregated, or could be adjusted to more reliable benchmarks prior aggregation. 
Whether the derived volume series are directly related to the target variable or are indirectly correlated, the most important selection criteria will be their ability to show short and long term tends that are as close as possible to the target variable. The ideal benchmark values to assess these properties against are the quarterly/annual GDP and component series in volume terms. The selection and assessment of data and elementary indicators should be conducted according to economic relevance of the components. This will lead to having specific focuses on data sources depending on countries' economic structures.

\section{Index compilation}

Economic transaction expressed in values (e.g. total dollars) can be directly summed up since they are expressed in the same unit of measure. Quantities may either be expressed in different units of measurement or be expressed in the same units but representing different qualities, and then are not directly additive. For example, it would be meaningless to compare over time the sum of barrels of crude oil with the megawatts generated by a hydro-plant. Similarly, it would be wrong to assume that the total production in volume terms of a refinery equals the sum of barrels of motor oil, barrels of diesel, and the barrels of gasoline. Therefore, to derive aggregate measures of different components expressed in quantities or volume terms, ${ }^{13}$ index numbers must be generated and subsequently aggregated using appropriate weights as to arrive at an overall measure of activity, e.g. a MIEG.

Volume indexes are intended to provide a comparison between two measures in a single figure. These comparisons include not only single transactions but multiple ones, so by using an index number we solve the issue of aggregating different volume measures. In the case of time series, indexes will be constructed as the ratio of values of the same variable but in different periods of time.

The relationship between individual indexes and the aggregate depends on the weight structure and the period in which the weights are applied. There are different index formulas for compiling volume estimates. The most often used is the Laspeyres formulation. For the purpose of consistency, the MIEG should apply the same formulation as that used in the QNA, however, for its simplicity and relatively less data dependency it would be recommendable to follow the Laspeyres formulation even if the QNA does not. The Laspeyres formula is as follows:

\footnotetext{
${ }^{13}$ Quantities represent the countable number of units of a single product, e.g. kilograms of red seedless grapes of certain size and origin. Volumes represent more generally an equalized figure that group several products (group of products), e.g. total amount (kilogram equivalent, or dollars of a fixed base period) of grapes. The volume value will include green, red, black and yellow grapes from different origins and sizes. Thus, quantities are volumes, but volumes are not necessarily quantities.
} 


$$
L_{Q}=\frac{\sum_{i=1}^{n} p_{i}^{0} q_{i}^{t}}{\sum_{i=1}^{n} p_{i}^{0} q_{i}^{0}} \equiv \sum_{i=1}^{n}\left(\frac{q_{i}^{t}}{q_{i}^{0}}\right) * w_{i}^{0}
$$

where $L Q$ is the aggregate volume index, $p$ represents prices, $q$ quantities, $i$ identifies the different component of the index ( $\mathrm{n}$ is the total number of components), $t$ is the current period of time, $O$ is the initial observation (addressed as the base or reference period), $w$ represents the weights (proportions) used to aggregate the quantity (or volume) relatives. ${ }^{14}$ Both definitions of $L_{Q}$ are identical. However, the left-hand formulation requires detailed information on quantities and prices, while the right-hand formulation only requires quantities or volumes and their respective weights.

The weights $(w)$ to aggregate the volume ratios represent the relative significance of each of the components in the total. When measuring economic activity, the weights should be derived as the proportion of each economic activity to the total final production. In the case of a MIEG, the weights are derived from the proportion of value added of each economic activity to the total GDP. To avoid distortions derived from seasonal patterns of unusual events, weights should be derived from the annual figures.

All elementary volume indicators can be directly aggregated using the value added weights, when available, to derive the respective activity indicator. However, when additional information (annual trends, quarterly patterns) on value added is available, it is possible to improve the indicator series by performing benchmarking on each of the component series to integrate such additional information prior the final aggregation.

Benchmarking methods align two measures of the same variable which are available in different frequencies. Its advantage relies on its ability to integrate the short-term dynamics embedded in the indicators series with the more reliable long term trends present in the quarterly/annual benchmarks. As a result, performing the method will produce consistent estimates that reflect both, the underlying long-term trend of the lower frequency references (benchmarks) and the high frequency dynamics from the indicator.

\section{Additional statistics can be derived if seasonal and calendar adjustment is} performed to the original results. This process transforms the series in a way such that contiguous observations (current to previous month) are more comparable. Calendar effects can be quite significant on a monthly basis, so its estimation is crucial and requires specific and proper estimation techniques. Given the conjunctural nature

\footnotetext{
${ }^{14}$ Although the original formulation is presented assuming individual product prices and quantities, it can be extended to volumes and deflators. Then the right-hand side can represent volume instead of quantity relatives.
} 
of short-term indicators, seasonal adjustment should be an integral part of the compilation process of a MIEG and it needs to be carefully performed.

\section{Index dissemination}

The MIEG is intended to give an overview of the economic activity as a whole. However, depending on the quality of the source data and on country's preferences, its dissemination can cover some detailed information on top of the headline aggregate, e.g. by major economic activity. If the index is disseminated in an aggregated from, descriptive text should provide more detailed information regarding the main drivers of the changes in the headline number.

The main advantages of an indicator of this nature are its timeliness and frequency. Therefore, to maximize its usefulness its dissemination should precede other comprehensive measures of activity such as the quarterly GDP.

Unadjusted as well as seasonally and calendar adjusted versions of the index should be made available. Considering users demands, the trend-cycle component could also be included. Analytical descriptive notes should accompany the data including revision analysis when appropriate. Sources and compilation methods should be available for users, including an advanced publication calendar. The revision policy, if any, should be consistent with the overarching policy.

\section{Conclusions}

High frequency -and timely- information is required to assess the current status of the economy. In particular, macroeconomic policy making requires monthly indicators of prices to assess inflation and activity measures to assess output gaps. Most countries compile monthly price statistics but lack monthly activity measures.

Central banks often develop business cycle indicators to approach the activity measures when statistical agencies do not have quality HFI. A business cycle approach can supplement more robust indicators of activity such as those compiled under the SNA approach. In fact, leading indicators are better suited to provide an anticipated signal of the cycle, while the current situation is usually better assessed based on actual measures, such as the QNA.

The SNA approach to measuring economic activity is broadly consistent with the annual and quarterly GDP compilation process; therefore, statistical agencies that compile annual and quarterly estimates are well placed to undertake this exercise. Nevertheless, inter-institutional efforts are usually required as a starting point to develop reliable activity indicators. 
The development of a MIEG will depend on available source data and on current national accounts resources. Exploiting new sources of information is an essential initial investment to carry out and whose benefits impact on other official statistics such as the QNA and some relevant HFI.

The relative greater methodological flexibility to compile a MIEG as compared to other macroeconomic statistics, together with its ability to include multiple and varied source data make of this indicator a good candidate for countries to develop regardless their level of statistical development. These indicators can be initially produced experimentally, and subsequently expanded and refined.

The experience in countries where these indicators are available shows that not only MIEGs have a place as one of the most relevant macroeconomic indicators, but also generates significant dynamic synergies with other macroeconomic statistics driving continued quality improvements and enhancements.

Strengthening high frequency economic activity measures contributes with surveillance and policy decision makings and supports the development and quality improvement of other key macroeconomic statistics. STA will continue providing assistance to develop new and enhance current MIEGs to IMF member countries, especially to low income countries. 
APPENDIX 1: AVAILABLE INDICATORS BY COUNTRY (TO BE COMPLETED)

\begin{tabular}{|c|c|c|}
\hline \multicolumn{2}{|c|}{ Centrally compiled and disseminated } & $\begin{array}{l}\text { Compiled and disseminated by } \\
\text { individual countries }\end{array}$ \\
\hline Conference Board & OECD & $\begin{array}{l}\text { Accounting Approach } \\
\text { (sample of countries) }\end{array}$ \\
\hline $\begin{array}{l}\text { Australia } \\
\text { Brazil } \\
\text { China } \\
\text { Euro Area } \\
\text { France } \\
\text { Germany } \\
\text { India } \\
\text { Japan } \\
\text { Korea } \\
\text { Mexico } \\
\text { Spain } \\
\text { U.K. } \\
\text { U.S. }\end{array}$ & $\begin{array}{l}\text { Australia } \\
\text { Austria } \\
\text { Belgium } \\
\text { Canada } \\
\text { Chile } \\
\text { Czech Republic } \\
\text { Denmark } \\
\text { Estonia } \\
\text { Finland } \\
\text { France } \\
\text { Germany } \\
\text { Greece } \\
\text { Hungary } \\
\text { Ireland } \\
\text { Israel } \\
\text { Italy } \\
\text { Japan } \\
\text { Korea } \\
\text { Mexico } \\
\text { Netherlands } \\
\text { New Zealand } \\
\text { Norway } \\
\text { Poland } \\
\text { Portugal } \\
\text { Slovak Republic } \\
\text { Slovenia } \\
\text { Spain } \\
\text { Sweden } \\
\text { Switzerland } \\
\text { Turkey } \\
\text { United Kingdom } \\
\text { United States } \\
\text { Brazil } \\
\text { China (People's Republic of) } \\
\text { India } \\
\text { Indonesia } \\
\text { Russia } \\
\text { South Africa }\end{array}$ & $\begin{array}{l}\text { Argentina (EMAE) } \\
\text { Armenia (IEA) } \\
\text { Brazil (IBC-Br) } \\
\text { Canada (GDP) } \\
\text { Chile (IMACEC) } \\
\text { Colombia (ISE) } \\
\text { Costa Rica (IMAE) } \\
\text { Ecuador (IDEAC) } \\
\text { Egypt (IPM) } \\
\text { El Salvador (IMAE) } \\
\text { Guatemala (IMAE) } \\
\text { Honduras (IMAE) } \\
\text { México (IGAE) } \\
\text { Nicaragua (IMAE) } \\
\text { Panamá (IMAE) } \\
\text { Paraguay (IMAEP) } \\
\text { Uganda (MCIEA) }\end{array}$ \\
\hline
\end{tabular}




\section{APPENDIX 2: DETAILED DATA SOURCES AND INDICATORS BY TYPE OF INDUSTRY}

Industry

Source

\begin{tabular}{|c|c|c|}
\hline \multirow{4}{*}{$\begin{array}{l}\text { Agriculture, forestry and } \\
\text { fishing }\end{array}$} & Ministry of Agriculture & \multirow{4}{*}{$\begin{array}{l}\text { Effective sowing, harvest projections, } \\
\text { product exports, output of specific } \\
\text { products, related activities (sawmills, } \\
\text { food processing industries - } \\
\text { intermediate consumption), fishing } \\
\text { quotas, imports (specific input } \\
\text { products). }\end{array}$} \\
\hline & Farmer associations & \\
\hline & Administrative records & \\
\hline & Customs & \\
\hline \multirow{3}{*}{$\begin{array}{l}\text { Manufacturing and } \\
\text { Mining }\end{array}$} & Statistical office & \multirow{3}{*}{$\begin{array}{l}\text { Industrial production index (IPI), } \\
\text { specific product outputs, related } \\
\text { activities (suppliers of relevant inputs), } \\
\text { and exports. }\end{array}$} \\
\hline & $\begin{array}{l}\text { Direct information from large } \\
\text { enterprises }\end{array}$ & \\
\hline & Business associations & \\
\hline \multirow{4}{*}{$\begin{array}{l}\text { Electricity, gas, water, } \\
\text { and waste management }\end{array}$} & Statistical office & \multirow{4}{*}{$\begin{array}{l}\text { Industrial production index (IPI), } \\
\text { administrative records on electricity } \\
\text { gas and water distribution, and } \\
\text { administrative record on waste } \\
\text { collection (though government } \\
\text { charges). }\end{array}$} \\
\hline & Ministry of Finance & \\
\hline & $\begin{array}{l}\text { Direct information from large } \\
\text { enterprises }\end{array}$ & \\
\hline & Customs & \\
\hline \multirow{3}{*}{ Construction } & Ministry of Finance & \multirow{3}{*}{$\begin{array}{l}\text { Building permits, government } \\
\text { investment, supply of construction } \\
\text { inputs, surveys of construction works } \\
\text { put in place, imports of specific inputs, } \\
\text { private investment reports of large } \\
\text { projects, records of public tenders. }\end{array}$} \\
\hline & Construction chamber & \\
\hline & Customs & \\
\hline \multirow{7}{*}{$\begin{array}{l}\text { Trade, Transportation, } \\
\text { and Accommodation } \\
\text { and food }\end{array}$} & Ministry of Transport & \multirow{7}{*}{$\begin{array}{l}\text { Wholesale and retail trade indexes, } \\
\text { tourist arrival and usage of hotels, } \\
\text { administrative records on cargo, } \\
\text { international passenger register, toll } \\
\text { records, related industries. }\end{array}$} \\
\hline & Ministry of Truism & \\
\hline & Statistical office & \\
\hline & Industry associations & \\
\hline & Balance of payments & \\
\hline & Customs & \\
\hline & Commerce chamber & \\
\hline \multirow[t]{2}{*}{$\begin{array}{l}\text { Information and } \\
\text { communication }\end{array}$} & Ministry of telecommunications & $\begin{array}{l}\text { Postal services records, administrative } \\
\text { records on telecommunications (phone } \\
\text { usage, land line subscription, internet } \\
\text { connections, cable TV subscriptions, } \\
\text { etc), and parcel service records } \\
\text { (national and international). }\end{array}$ \\
\hline & Superintendence of Banks & \\
\hline
\end{tabular}




\begin{tabular}{|c|c|c|}
\hline \multirow{2}{*}{$\begin{array}{l}\text { Financial and insurance } \\
\text { activities }\end{array}$} & Central Bank & \multirow{2}{*}{$\begin{array}{l}\text { Loan and deposits by institution; } \\
\text { premiums, claims and maturity by type } \\
\text { of insurance contract. }\end{array}$} \\
\hline & Superintendence of Insurance & \\
\hline $\begin{array}{l}\text { Real estate, } \\
\text { Professional, and } \\
\text { supporting services }\end{array}$ & Statistical office & $\begin{array}{l}\text { Employment, register of realtors, } \\
\text { administrative records on changes of } \\
\text { ownerships, legal cases, register of } \\
\text { veterinaries, travel and employment } \\
\text { agencies, related industries. }\end{array}$ \\
\hline $\begin{array}{l}\text { Public administration } \\
\text { and defense; } \\
\text { compulsory social } \\
\text { security }\end{array}$ & Ministry of finance & $\begin{array}{l}\text { Wages and salaries, employment by } \\
\text { level and public entity, social security } \\
\text { contributions. }\end{array}$ \\
\hline Education & Ministry of Education & $\begin{array}{l}\text { Enrolment by type of institution, } \\
\text { employment by type of institution, } \\
\text { wages and salaries. }\end{array}$ \\
\hline $\begin{array}{l}\text { Human health and social } \\
\text { work activities }\end{array}$ & Ministry of health & $\begin{array}{l}\text { Use of services by type of care, usage } \\
\text { of hospital beds, health insurance } \\
\text { companies, related industries, register } \\
\text { of rest-homes (licenses), direct } \\
\text { subsidies. }\end{array}$ \\
\hline \multirow{2}{*}{ Other service activities } & Ministry of finance & \multirow{2}{*}{$\begin{array}{l}\text { Employment, direct subsidies (from } \\
\text { government, private entities and from } \\
\text { abroad). }\end{array}$} \\
\hline & Statistical office & \\
\hline
\end{tabular}




\section{APPENDIX 3: AVAILABILITY OF STATISTICS BY GEOGRAPHICAL AREA}

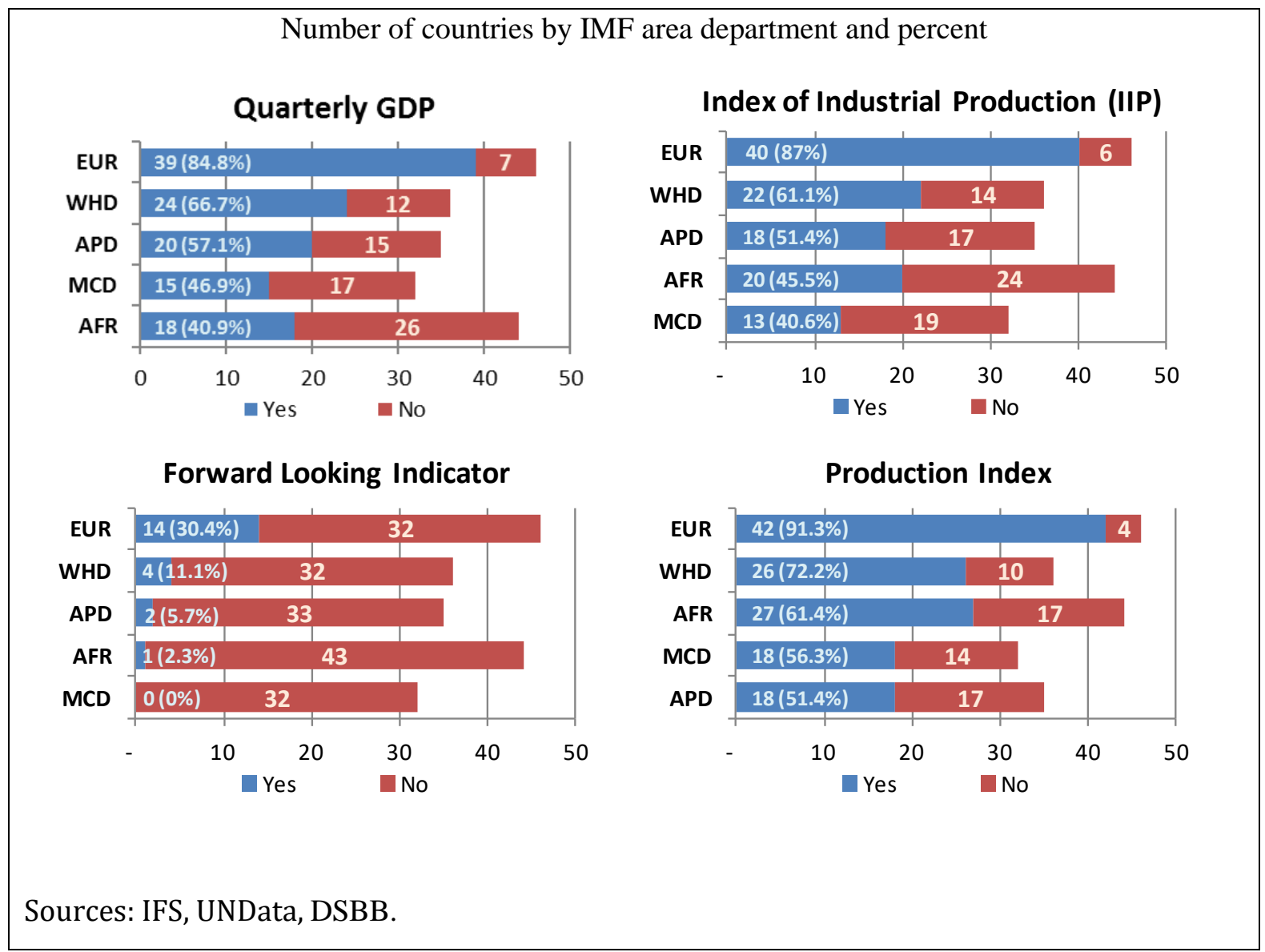




\section{APPENDIX 4: OTHER High FREQUENCY INDICATORS OF ACTIVITY}

Business cycle indicators are compiled to support decision making. These types of indicators are compiled by domestic public or private institutions and also by third parties. The US conference board for instance compiles three types of indicators for its member countries: Leading, concurrent and lagging indicators. Depending on the ability of each of the component series to anticipate, concurrently estimate, or confirm past turning points, such components are grouped to provide a single cyclical indicator. Currently the US Conference Board disseminates indicators for 12 of its members and for the Euro Area.

For example, the component series (9) of the leading indicator for the US are: Average weekly hours, manufacturing; Average weekly initial claims for unemployment insurance; Manufacturers' new orders, consumer goods and materials; ISM new order index; Building permits, new private housing units; Stock prices, 500 common stocks; Leading Credit Index; Interest rate spread, 10-year Treasury bonds less federal funds; and Average consumer expectations for business and economic conditions. In turn, the components series (4) of the coincident indicator are: Employees on nonagricultural payrolls; Personal income less transfer payments; Industrial production; and the Manufacturing and trade sales.

Among the Main Economic Indicators (MEI), the OECD compiles and disseminates Composite Leading Indicators (CLI) for 33 member countries (Iceland is not included), 6 non-member economies and 8 zone aggregates.

The CLI is a monthly times series, formed by aggregating a variety of country specific component indicators which show a reasonably consistent relationship with a reference series ${ }^{15}$ (e.g. industrial production IPI) at turning points. The OECD CLI is designed to provide qualitative information on short-term economic movements, especially at the turning points, rather than quantitative measures. As a means of example, the component series (7) for the US CLI are: Permits issued: dwellings; Net new orders for durable goods; Share prices: NYSE composite; Consumer sentiment indicator; Weekly hours of work: manufacturing; Purchasing managers index; and the Spread of interest rates.

The term high frequency indicators is used in IMF publications to describe a range of high frequency statistics (such as indicators to assess systemic financial risk; bank stress; inflation targeting). In addition, Fund staff have developed indicators of

\footnotetext{
${ }^{15}$ True estimates of the business cycle can be derived from the quarterly GDP estimates. But quarterly figures can shift turning points, so a more precise estimate of the trend cycle should be derived from monthly figures of activity.
} 
economic activity for surveillance. For example, Matheson (2011) uses a dynamic factor model to derive indicators for 32 advanced and emerging market economies. Dynamic factor models utilize a large number of economic time series and produce reliable short-term forecasts of the cycle. ${ }^{16}$

Opoku-Afari and Dixit (2012) uses a composite index of economic activities as an input to interpolating quarterly GDP series. ${ }^{17}$ The method is a modified version of the US Conference Board methodology to estimate coincident indicators. It is applied to a selected number of sub-Saharan countries and attempts to work around the data constraints faced by low income countries.

The 2013 Article IV Consultation for Suriname presents a "parsimonious model including credit and a proxy for global conditions" to derive a monthly indicator of GDP. The report notes fittingly, that the more complex econometric methods as used by Matheson, cannot be applied due, in part, to data constraints. ${ }^{18}$

The Eastern Africa Regional Technical Assistance Centers is developing composite indexes of economic activity. Their approach is broadly based on the US Conference Board methodology but includes mostly output figures as input data. In this sense, cyclical movements are derived from directly related activity data as supposed to the original approach that derives the cyclical movements from behaviorally related series.

The IMF's efforts on deriving monthly activity composite indicators have relied on either the statistic or econometric approaches. In general terms, regardless of the approach used to estimate the cyclical component of the economic activity, it requires a comparative "true" cyclical movement. Thus, a prerequisite to assess cycle-tracker indicators is to have a well-established statistical system to derive reliable business cycle analysis. If no robust benchmarks are available, estimated indicators are not directly assessable and therefore, not reliable in terms of the signals they produce.

\footnotetext{
${ }^{16}$ Matheson, T, 2011, "New Indicators for Tracking Growth in Real Time" IMF Working Paper 11/43

${ }^{17}$ Opoku-Afari, M and Dixit, S, 2012 "Tracking Short-Term Dynamics of Economic Activity in Low-Income Countries in the Absence of High-Frequency GDP Data" IMF Working Paper 12/110

${ }^{18}$ IMF, 2013 "Suriname: 2013 Article IV Consultation”, IMF Country Report No. 13/341
} 


\section{REFERENCES}

International Standard Industrial Classification of All Economic Activities, Rev.4 (http://unstats.un.org/unsd/cr/registry/isic-4.asp)

Business Cycle Indicators Handbook, The Conference Board (https://www.conferenceboard.org/pdf_free/economics/bci/BCI-Handbook.pdf)

Central Product Classification (CPC) Ver.2.1 (http://unstats.un.org/unsd/cr/registry/cpc21.asp)

Compilation Manual for an index of Services Production (http://www.oecd.org/std/businessstats/37799074.pdf)

Handbook on Constructing Composite Indicators (http://www.oecd.org/std/42495745.pdf)

IMF, 2013 “Suriname: 2013 Article IV Consultation”, IMF Country Report No. 13/341

(http://www.imf.org/external/pubs/ft/scr/2013/cr13341.pdf)

International Recommendations for the Index of Industrial Production 2010

(http://unstats.un.org/unsd/statcom/doc10/BG-IndustrialStats.pdf)

Matheson, T, 2011, "New Indicators for Tracking Growth in Real Time" IMF Working Paper 11/43 (https://www.imf.org/external/pubs/ft/wp/2011/wp1143.pdf)

OECD System of Composite Leading Indicators (http://www.oecd.org/std/leadingindicators/41629509.pdf)

Opoku-Afari, M and Dixit, S, 2012 "Tracking Short-Term Dynamics of Economic Activity in Low-Income Countries in the Absence of High-Frequency GDP Data” IMF Working Paper 12/110 (https://www.imf.org/external/pubs/ft/wp/2012/wp12119.pdf)

Quarterly National Accounts Manual Concepts, Data Sources, and Compilation (https://www.imf.org/external/pubs/ft/qna/) 